\title{
The Influence of a University Homeschool Physical Education Program on Fundamental Motor Skills and Self-Confidence
}

\author{
Matthew Buns ${ }^{1} \&$ Kallie LaValle ${ }^{1}$ \\ ${ }^{1}$ Department of Kinesiology and Health Sciences, Concordia University, Saint Paul, USA \\ Correspondence: Matthew Buns, Department of Kinesiology and Health Sciences, Concordia University, Saint \\ Paul, MN, USA. Tel: 1-65-1641-8472.
}

Received: April 15, 2020

Accepted: May 7, 2020

Online Published: May 15, 2020

doi:10.20849/jed.v4i2.737

URL: https://doi.org/10.20849/jed.v4i2.737

\begin{abstract}
Individuals are both more likely to participate in sports, exercise, and physical activity when they are skilled. Therefore, motor skills and skilled movement should be viewed as prerequisites to a physically active lifestyle. Children and adolescents who have achieved fundamental motor competence are also believed to perceive themselves as being competent although there is inconsistency in the results so far reported in the literature. Despite the unprecedented growth home homeschool education, studies have not examined the development of motor competency of homeschool students or its relationship to confidence. The current investigation examined the influence fundamental motor skill development and self-confidence of students enrolled in a university homeschool physical education program. Results from the pre-test $(\mathrm{M}=13.92, \mathrm{SD}=2.8)$ and post-test $(\mathrm{M}=$ $20.75, \mathrm{SD}=3.5$ ) fundamental motor skill observations indicate that the homeschool program led to an improvement in overall skill, $\mathrm{t}(52)=12.05, \mathrm{p}<.001$ (E.S. $=1.06$ ). Dependent-samples $t$-test produced significant results from pre to post for research participants $[\mathrm{t}(1,52)=27.26, \mathrm{p}<.05$, E.S. $=1.10]$, who improved their self-efficacy over the course of the study [baseline $\mathrm{M}$ self-efficacy $=71.92, \mathrm{SD}=16.52$, endline $\mathrm{M}$ self-efficacy $=$ $88.87, \mathrm{SD}=15.34]$. This study showed that a university homeschool physical education program can lead to improvements in the developmental of fundamental motor skills and self-confidence.
\end{abstract}

Keywords: homeschool, self-efficacy, assessment, competency, development, sports

\section{Introduction}

Historically, the role of physical education in the school curriculum is to help students develop the competencies and beliefs necessary for incorporating regular physical activity into their daily lives (Siedentop, 2002). Traditional physical education programs have typically emphasized the development of fundamental motor skills (running, catching, throwing, etc.) as the foundation for more complicated sport and movement skills later in life (Rink, 1993). Without fundamental motor kill competence, students are less likely to learn related sport and movement skills. Theefore, skilled movement is viewed as a prerequieste to a physically active lifestyle.

The scientific basis of skill acquisition and the development of expertise has been examined from a number of perspectives. Skill acquisition is a gradual process and becoming proficient requires opportunities for practice and feedback (McKenzie et. al, 1998). Older children are typically more skilled than those who are younger, and males tend to perform better on motor skill tests than females (Haubenstricer \& Seefeldt, 1986). Gender differences before puberty not thought to be linked to biology, rather are the result of varying opportunities, expectations, and encouragement (Thomas, Thomas, \& Gallagher, 1993), raising the likelihood that gender differences can be reduced through increased practice and improved instruction.

Studies have also investigated how confidence and other psychological variables are associated with mastery of fundamental motor skills during childhood. Individuals who have developed higher levels of fundamental motor competence are believed to be more confident to have a positive attitude towards physical activity (Nobrea, Bandeira, \& Valentini, 2016). However, there is inconsistency in the results so far reported in the literature: sometimes they provide support to the relationships between motor performance and confidence (Weiss et al, 2005) and, in other occasions, they question it (Spessato, et al., 2013). This disparity has been attributed to the poor specific of scales of children's self-efficacy which likely reflects on the weakened relationships with motor skills. 
Universities are actively seeking new ways to provide meaningful field experience opportunities for students. One such opportunity includes partnerships with community homeschooling parents and children (Buns, Pettit \& Blanton, 2017). According to the National Home Education Research Institute (2010), homeschooling has grown from nearly extinct in the United States in the 1970's to now over two million school-aged students. The same report states the seven percent growth rate for homeschool education far exceeds the 0.59 percent growth rate of traditional school enrollment (from 2007-2010).

It is important to note that fundamental motor skills are not acquired naturally and they must be taught (Isaacs \& Payne, 2002). Without access to a physical activity program such as public school physical education, homeschool children may forego an opportunity to improve health and consequently be at greater risk for cardiovascular disease and adiposity (Long et al., 2010). Unfortunately, studies investigating the efficacy of homeschool physical education programs are scare, inconclusive, and the results tend to focus on physical activity rather than fundamental motor skill (Swenson et al., 2016; Welk et al., 2004; Devoe \& Kennedy, 1995).

Studies investigating skill levels of homeschool children are extremely rare. Research suggests that as children gain confidence in performing fine and gross motor skills, and build a sufficiently diverse movement repertoire, they acquire a high level of movement proficiency that is positively associated with quality of their psychomotor and cognitive health (Chaddock-Heyman et al., 2013). When low skilled students experience failure, their most common response is to stop engaging in the activity (Portman, 1995). Bandura (1977) has suggested that it provokes behavioral change. For this reason, it is important to assess fundamental motor skill proficiency and self-efficacy towards skill to gain a better understanding of this emergent relationship between skill proficiency and self-confidence. However, the influence physical self-efficacy has on fundamental motor skills in homeschool children and adolescents is uncertain because research examining the competency-confidence relationship has been riddled with methodological shortcomings.

Understanding how critical fundal motor skill development is to a physically active lifestyle, there is a need for better understanding the motor competency of homeschool students and capture the effective of homeschool physical education programs. Despite the unprecedented growth home homeschool education, studies have not examined the development of motor competency of home school students or its relationship to confidence. With this in mind, the current investigation focuses on fundamental motor skill development of students enrolled in a university homeschool physical education program. A secondary purpose was to investigate the relationship between motor competence and self-efficacy related to the task. A tertiary purpose of the study was to explore the development of children's motor skills by age and gender.

\section{Method}

\subsection{Participants}

The participants in this study consisted of homeschool students aged between 6 and 16 years old from four developmentally-appropriate classes at a university homeschool sport development program. The classes met once per week during a period of eight weeks each semester (fall and spring) for a total of 16 lessons over two semesters. Each lesson was scheduled for 60 minutes located at a university setting a large metropolitan area in the upper Midwest. The teachers of all four classes consisted of physical education pre-service teachers with faculty supervision. The project was approved by the Institutional Review Board, Human Subjects Review Committee. Informed consent (and assent for minors) was obtained from all participants.

\subsection{Procedures}

Three types of data were collected: 1) participants experience with sport and physical activity, 2) participant's self-efficacy towards performance in physical education, and 3) participant's technical performance in five fundamental motor locomotor skills (catching, throwing, running, jumping, and kicking). Data was collected prior to the first lesson (baseline) and following completion of the 8-week program (endline). See Figure 1 for a complete overview of lesson content for each grade level.

\begin{tabular}{c|cc}
\hline Session & \multicolumn{2}{c}{ Lesson Focus } \\
\hline \multirow{2}{*}{1} & $\mathrm{~K}-1$ & Manipulative Skills Using Hoops \\
\hline & $2-3$ & Throwing Skills/Games \\
\hline $4-6$ & Football Skills and Lead-up Activities \\
\hline $7-12$ & Soccer or Flag Football Skills and Lead-up Activities \\
\hline
\end{tabular}




\begin{tabular}{|c|c|c|}
\hline \multirow[t]{4}{*}{2} & $\mathrm{~K}-1$ & Throwing Skills/Games \\
\hline & $2-3$ & Manipulative Skills Using Wands and Hoops \\
\hline & $4-6$ & Long-Rope Jumping Skills/Games \\
\hline & $7-12$ & Soccer or Flag Football Game Play \\
\hline \multirow[t]{4}{*}{3} & $\mathrm{~K}-1$ & Manipulative Skills Using Beanbags \\
\hline & $2-3$ & Football Skills and Lead-up Activities \\
\hline & $4-6$ & Soccer Skills and Lead-up Activities \\
\hline & $7-12$ & Volleyball Skills and Lead-up Activities \\
\hline \multirow[t]{4}{*}{4} & $\mathrm{~K}-1$ & Manipulative Skills Using Playground Balls \\
\hline & $2-3$ & Soccer Skills and Lead-up Activities \\
\hline & $4-6$ & Gymnastics skills \\
\hline & $7-12$ & Volleyball Game Play \\
\hline \multirow[t]{4}{*}{5} & $\mathrm{~K}-1$ & Movements Skills/Games \\
\hline & $2-3$ & Fundamental Skills Using a Parachute \\
\hline & $4-6$ & Basketball Skills and Lead-up Activities \\
\hline & $7-12$ & Badminton Skills and Lead-up Activities \\
\hline \multirow[t]{4}{*}{6} & $\mathrm{~K}-1$ & Gymnastics Skills \\
\hline & $2-3$ & Rhythmic Movement Skills \\
\hline & $4-6$ & Rhythmic Movement Skills \\
\hline & $7-12$ & Badminton Game Play \\
\hline \multirow[t]{4}{*}{7} & K-1 & Kicking, Trapping, Bowling, and Rolling \\
\hline & $2-3$ & Gymnastics Skills \\
\hline & $4-6$ & Throwing Skills/Games \\
\hline & $7-12$ & Speed-Away \\
\hline \multirow[t]{4}{*}{8} & $\mathrm{~K}-1$ & Fundamental Skills Using Parachute Activities \\
\hline & $2-3$ & Hockey Skills and Lead-up Activities \\
\hline & $4-6$ & Cooperative Game Skills \\
\hline & $7-12$ & Team Handball Skills and Game Play \\
\hline
\end{tabular}

Figure 1. Lesson focus for the four age groups in the homeschool physical education program

\subsection{Instruments}

\subsubsection{Demographic Questionnaire (Pre-and Post)}

Participants were asked questions regarding their physical education and physical activity experiences. Other questions will related to demographic information such as age, gender, etc.

\subsubsection{Self-Efficacy Scale (Pre-and Post)}

Participants self-efficacy towards understanding, performance, and enjoyment in physical education was assessed following Bandura's (1995) guidelines for assessing the strength of efficacy beliefs (Figure 2). Responses were recorded using a 100-point scale, ranging in 10-unit intervals from 0 ("Cannot do"); through intermediate degrees of assurance, 50 ("Moderately certain to do"); to complete assurance, 100 ("Certain can do"). 


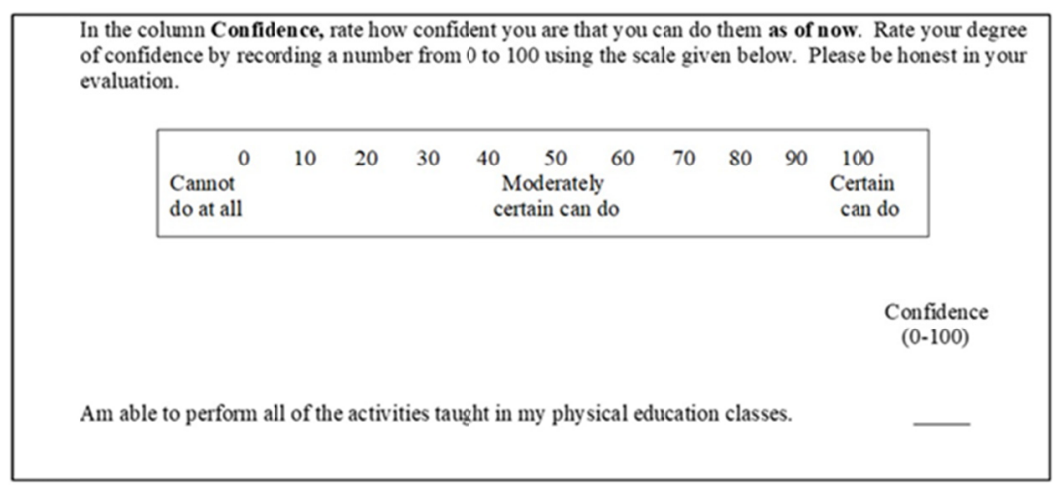

Figure 2. Self-efficacy scale towards performance in physical education

\subsubsection{Skill Testing (Pre-and Post)}

In assessing the student's technical competence, two observers were trained to quantitatively evaluate student performance. Skill assessment took approximately one hour and occurred in within one week of the first class (baseline) and within one week following the final class (endline). Figure 3 provides a list of the performance criteria assessed for each skill. In making this evaluation, the components for each skill were scored as "appropriate (score $=1$ ) or "inappropriate" (score $=0)$. The final score for each skill was provided by the sum of all the appropriate executions to each of the technical components

\section{Catch}

Eyes are focused on the ball throughout the catch

Preparatory position with elbows bent and hands in front of body

Hands move to meet the ball

Hands move to meet the ball

Catch and control the ball with hands only

Elbows bend to absorb force of the ball

\section{Kick}

Eyes are focused on the ball throughout the kick

Step forward with non-kicking foot placed near ball

Bend knee of kicking leg during the backswing for the kick

Hip extension and knee flexion of at least 90 degrees

Contact the ball with the top of the foot

Forward and sideward swing of arm opposite kicking leg

Kicking leg follows through towards the target after ball contact

\section{Run}

Eyes focused forward throughout the run

Knees bend at right angles during the recovery phase

Arms bend at elbows and move in opposition to legs

Contact ground with front part of foot

Body leans slightly forward

\section{Vertical Jump}

Eyes focused forwards or upwards throughout the jump 
Crouch with knees bent and arms behind body

Forceful upward thrust of arms and legs straighten to take off

Contact ground with front part of feet and bend knees to absorb force of landing

Balanced landing with no more than one step in any direction

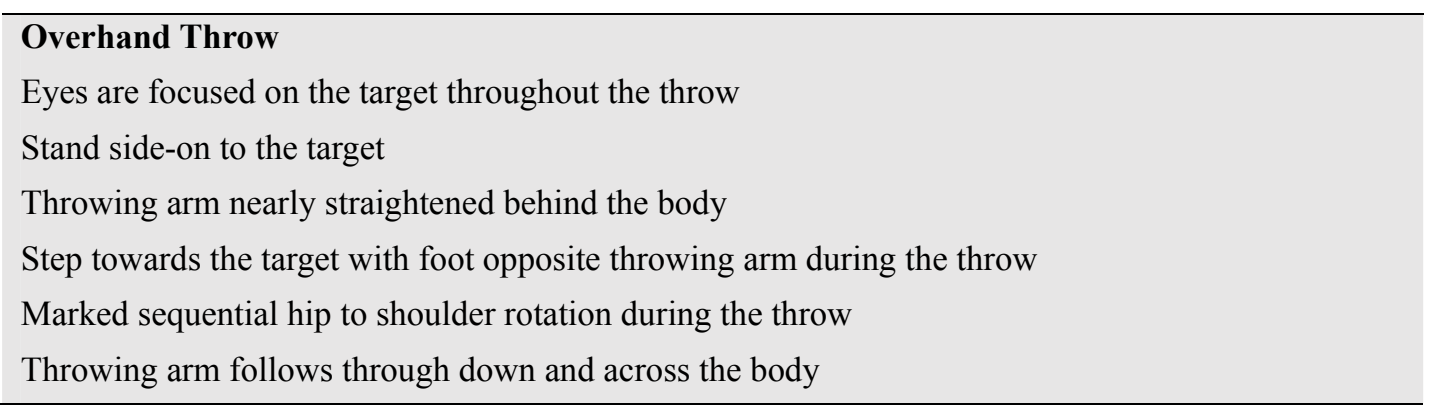

Figure 3. List of criteria assessed for motor performance

\subsection{Data Analysis}

Descriptive statistics captured critical participant characteristics. The study design was a simple pre-post design with an intervention of eight homeschool sport development sessions. Dependent-sample $t$-tests were used to test differences in self-efficacy and skill from baseline to end line. Pearson product-moment correlation analyses were conducted to identify the participant correlates (e.g., age, gender, self-efficacy) related to the psychomotor performance outcomes. All statistical analyses were completed using SPSS (version 25.0; IBM, Inc., Chicago, IL, USA) with an alpha of $\mathrm{p} \leq 0.05$. Values are expressed as mean $\pm \mathrm{SD}$.

\section{Results}

Of the 68 participants that started the study, 53 participants (mean age $=10.47, \mathrm{SD}=2.81$ ) that were able to complete all sessions and therefore included in the analysis. There was an unequal number of males $(\mathrm{n}=32)$ and females $(n=21)$. Table 1 shows descriptive data for the participants in this study. Outcome measure were deemed normally distributed after examining skewness, kurtosis, and Q-Q plots within each group.

Table 1. Descriptive data for participant demographic information by gender

\begin{tabular}{llllll}
\hline & & & \multicolumn{3}{l}{$95 \%$ Confidence Interval } \\
\hline Group & Factor & $\mathrm{M}$ & $\mathrm{SD}$ & Lower Boundary & Upper Boundary \\
\hline Males (n=32) & Age & 10.31 & 2.98 & 6.00 & 16.00 \\
\cline { 2 - 6 } & Height (inches) & 55.17 & 5.96 & 48.00 & 66.00 \\
\cline { 2 - 6 } & Weight (pounds) & 73.33 & 22.41 & 42.00 & 120.00 \\
& Physical Activity* & 0.78 & 0.98 & 0.00 & 7.00 \\
\hline Females (n=21) & Age & 10.71 & 2.59 & 7.00 & 15.00 \\
& Height (inches) & 57.16 & 4.70 & 47.00 & 63.50 \\
& Weight (pounds) & 86.06 & 37.14 & 42.00 & 138.00 \\
& Physical Activity* & 1.10 & 0.99 & 0.00 & 5.00
\end{tabular}

Note 1. Physical activity refers to self-reported organized sport/physical education hours per week (hours)

Dependent samples t-tests were used to determine if participant fundamental motor skills changed from pre to post. The overall results from the pre-test $(\mathrm{M}=13.92, \mathrm{SD}=2.8)$ and post-test $(\mathrm{M}=20.75, \mathrm{SD}=3.5)$ fundamental motor skill observations indicate that the homeschool physical education program resulted in an improvement in overall skill, $\mathrm{t}(52)=12.05, \mathrm{p}<.001$. Univariate analysis of variance (ANOVA) indicate no significant motor skill differences between boys and girls at baseline $[\mathrm{F}(52)=1.90, \mathrm{p}=.17]$ or endline $[\mathrm{F}(52)=$ $1.37, \mathrm{p}=.25$ ]. Table 2 displays a summary of the specific skill changes noted from pre to post. 
Table 2. Summary of fundamental motor skill test results and effect size from pre to post

\begin{tabular}{|c|c|c|c|c|c|c|}
\hline \multirow[t]{2}{*}{ Test } & \multicolumn{2}{|c|}{ Baseline } & \multicolumn{4}{|c|}{ Endline } \\
\hline & $\mathrm{M}$ & SD & $\mathrm{M}$ & SD & $\mathrm{t}$ & ES \\
\hline Catching & 2.47 & 1.28 & 4.06 & 1.22 & $7.01 * *$ & 1.27 \\
\hline Throwing & 3.32 & 1.42 & 4.17 & 1.09 & $3.76^{* *}$ & 0.67 \\
\hline Running & 2.53 & 1.40 & 4.42 & 1.32 & $6.72 * *$ & 1.39 \\
\hline Jumping & 3.02 & 1.34 & 4.26 & 1.26 & $5.57 * *$ & 0.95 \\
\hline Kicking & 2.59 & 1.41 & 3.85 & 1.08 & $5.24 * *$ & 1.00 \\
\hline
\end{tabular}

Note $1 . * p<.05$

Note $2 . * * p<.01$

To determine is participant self-efficacy changed from pre to post, a dependent samples $t$-test was used with the self-efficacy scale as the dependent variable. The test produced significant results from pre to post for research participants $[\mathrm{t}(1,52)=27.26, \mathrm{p}<.05$, E.S. $=1.10]$, who improved their self-efficacy over the course of the study [baseline $\mathrm{M}$ self-efficacy $=71.92, \mathrm{SD}=16.52$, endline $\mathrm{M}$ self-efficacy $=88.87, \mathrm{SD}=15.34]$. Univariate analysis of variance (ANOVA) indicate no significant self-efficacy differences between boys and girls at baseline $[\mathrm{F}(52)$ $=0.19, \mathrm{p}=.66]$ or endline $[\mathrm{F}(52)=2.34, \mathrm{p}=.13]$.

Pearson product-moment correlation regression equation analyses were conducted to identify the participant characteristics and correlates contributing to psychomotor skill (Table 3). The correlation analysis revealed a number of statistically significant relationships. The strongest relationship to psychomotor skills identified was that baseline total skill score (pre) was significantly related to weight $(r=0.48, p=.01)$ and height $(r=0.45, p=.01)$ but there was not relationship between self-efficacy and motor competency.

Table 3. Summary of fundamental motor skill test results and effect size from pre to post

\begin{tabular}{|c|c|c|c|c|c|c|c|c|c|c|}
\hline Variable & 1 & 2 & 3 & 4 & 5 & 6 & 7 & 8 & 9 & 10 \\
\hline 1. Age & & - & & & & & & & & \\
\hline 2. Gender & .07 & & & & & & & & & \\
\hline 3. Height & .12 & -.19 & $\ldots$ & & & & & & & \\
\hline 4. Weight & -.01 & -.21 & $.85 * *$ & & $\ldots$ & & & & & \\
\hline 5. Self-Efficacy (Pre) & & & .01 & -.19 & .12 & .18 & $\ldots$ & & & \\
\hline 6. Self-Efficacy (Post) & & & -.03 & -.16 & .11 & .15 & $.96^{* *}$ & & - & \\
\hline 7. Skill (Pre) & & .11 & .06 & $.45^{* *}$ & & $.48 * *$ & & -.22 & -.21 & $\ldots$ \\
\hline 8. Skill (Post) & & $.37 *$ & .21 & .17 & .05 & -.04 & -.02 & & .16 & $\ldots$ \\
\hline
\end{tabular}

Note 1. ** Correlation is significant at the .01 level (2-tailed)

Note $2 .{ }^{*}$ Correlation is significant at the .05 level (2-tailed)

\section{Discussion}

The purpose of this study was to address the question of whether a university sponsored homeschool physical education program can influence fundamental motor skill competency or self-confidence. To the best of our knowledge, no previous studies have examined the relationship between physical education participation and achievement of motor competency among homeschool children and adolescents. This research suggests that homeschool physical education programs can be an effective mechanism for increasing both fundamental motor skill and self-confidence in children and adolescents. Results indicate that the five fundamental motor skills assessed were positively influenced by a 16-week homeschool physical education program. The effect sizes in Table 2 show that the program had a large and meaningful effect of skill improvement (Cohen, 1977). The large effect sizes for running (1.39), catching (1.27), kicking (1.00), jumping (0.95), and throwing (0.67) suggest the 
program also had a meaningful influence on the outcome of fundamental skill development. This is noteworthy because the time for the intervention was relatively short (eight 60-minute sessions) and the intervention was led by non-certified pre-service teachers (with faculty supervision).

Previous literature has shown that university homeschool physical education programs may contribute to increasing physical activity levels (Swenson et al., 2016) and fitness (Long et al, 2010) but research has not examined the development of motor competency for homeschool students. These results demonstrate meaningful differences in the skill test scores from pre- to post intervention. There were no skill-related differences between boys and girls at baseline or endline. This study supports previous research that intervention effects did not differ by gender or age. Contrary to the findings of this study, previous literature suggests gender differences in fundamental motor skills (McKenzie et al., 1998). This study supports the idea that university homeschool physical education programs can be used to increase physical movement skills from fall to spring.

Fundamental motor skills have been described as the basic observable building blocks for movement (Cohen et al., 2014). These provide the foundation for the specialized, and sport-specific movement skills required for participation in a variety of physical activities including games, sports, and recreational activities. Despite fundamental motor skills contributing to the general development and wellbeing of children and adolescents, previous literature consistently illustrates that proficiency in fundamental motor skills is low, with only $50 \%$ of children demonstrating competency in a broad range of skills (Gallahue et al., 2012). Participants in this study met $48 \%(\mathrm{M}=13.92)$ of the 29 skill performance criteria required for mastery (from Table 3 ) at baseline and improved to $71 \%$ at endline $(\mathrm{M}=20.75)$. This $23 \%$ percent improvement in skill for homeschool children is larger than the $13-21 \%$ gain scores noted in the classic physical education program intervention conducted by McKenzie et al. (1998). One possibly for this rapid growth is that homeschool children may report lower motor proficiency at baseline compared to public school children who receive more structured physical activity opportunities. Despite these findings, questions still remain with respect to uncovering those aspects of the teaching and learning dynamics within any instructional model that promote homeschool student's skill development. This research should be accomplished using a more sophisticated design including qualitative analysis and a control group to further establish a cause-effect relationship.

The lower levels of fundamental motor proficiency at baseline may have translated into a lack of confidence in performing fundamental motor skills. Previous research suggests that without fundamental motor skill proficiency and a positive perception of such, children may be less likely to engage in physical activity (Lubans et al., 2010). Various studies have examined the relationship between self-confidence and actual movement competence (Babic et al., 2014), generally noting a positive relationship between skill and fundamental motor skill competence. Self-efficacy scores did improve significantly (by about 17\%) from pre to post (effect size = 1.10). This is consistent with previous research suggesting perceived competence can improve the acquisition of fundamental motor skills, because performers are more likely to engage in activities for which they feel skillfull and competent (Stodden et al., 2008).

In this study, no correlation was found between self-efficacy and actual motor competence (Table 3). Contrary to previous research involving public school children, there was not a relationship between pre or post self-efficacy and motor competency for participants in this study. This suggests that homeschool student perceptions of fundamental motor patterns are not associated with their actual proficiency. This lack of association in the current study can perhaps be explained by the mean age of participants ( $M=10.47$ years; $\mathrm{SD}=2.81$ ). It is also possible that younger children may not have the developmental or cognitive capacity to effectively perceive skill-related competence (Barnett et al., 2015).

\subsection{Limitations}

One limitation of the study is that the fundamental motor skill evaluations were not conducted by ceritified physical education instructors or professional movement professionals. Furthermore, motor skills were assessed in isolation and not during game play which is generally considered a more valid measure of program effectiveness (Rink et al., 1996). The measurement of the skills in controlled conditions (low external validity), however, was a strength, in that the established performance setting was standardized across all participants during two different measurement periods (high internal validity). Another limitation of this study is the use of a convenience sample, which can lead to the under-representation or over-representation of particular groups within the sample. In addition, the skill analyses were performed by pre-service physical education majors and not highly qualified or certified professional physical education teachers or movement experts. A final limitation of the present study is its lack of a control group, making it statistically impossible to establish a cause-effect relationship. To gain more understanding of the nature of these associations and to understand how relationships 
between these variables may change over time, experimental and longitudinal studies should be conducted.

\subsection{Future Research}

Future investigations should work to increase the understanding of homeschool children's perceived and actual movement skill proficiency with validated instruments for skill and self-efficacy during this phase of development. The elementary years are considered a "window of opportunity" for children (even if low-skilled) can be eager participants in physical activity (LeGear et al., 2012).

\subsection{Summary}

This study showed that a university homeschool physical education program can lead to improvements in the developmental of fundamental motor skills. This study also suggests that certain structural features of the program provide higher levels of self-efficacy which may explain some of the improvements made by lower-skilled students. It is important that homeschool children learn fundamental skills early in life, because they are prerequisites to successful participant in many sports and may be associated with increased health-related physical activity that continues into adulthood. The role that university homeschool partnerships play in develop skills and self-confidence appears to be strong.

\section{References}

Babic, M. J., Morgan, P. J., Plotnikoff, R. C., Lonsdale, C., White, R. L., \& Lubans, D. R. (2014). Physical activity and physical self-concept in youth: systematic review and meta-analysis. Sports Medicine, 44, 1589-1601. https://doi.org/10.1007/s40279-014-0229-z

Bandura, A. (Ed.). (1995). Self-efficacy in changing societies. Cambridge University Press. https://doi.org/10.1017/CBO9780511527692

Chaddock-Heyman, L., Erickson, K. I., Voss, M. W., Knecht, A. M., Pontifex, M. B., Castelli, D. M., ... Kramer, A. F. (2013). The effects of physical activity on functional MRI activation associated with cognitive control in children: a randomized controlled intervention. Front Hum Neurosci, 7, 72. https://doi.org/10.3389/fnhum.2013.00072

Cohen, J. (1997). Statistical power analysis for the behavioral sciences. New York: Academic Press.

Gallahue, D. L., Ozmun, J. C., \& Goodway, J. (2012). Understanding Motor Development: Infants, Children, Adolescents, Adults. New York: McGraw-Hill.

Haubenstricker, J., \& Seefeldt, V. (1986). Acquisition of motor skills during childhood. In V. Seefeldt (Ed.), Physical activity and well-being (pp. 41-102). Reston, VA: American Alliance for Health, Physical Education, Recreation, and Dance.

LeGear, M., Greyling, L., Sloan, E. et al.. (2012). A window of opportunity? Motor skills and perceptions of competence of children in Kindergarten. Int $J$ Behav Nutr Phys Act, 9, 29. https://doi.org/10.1186/1479-5868-9-29

Long, D. E., Gaetke, L. M., Perry, S. D., Abel, M., \& Clasey, J. L. (2010). The Assessment of Physical Activity and Nutrition in Home Schooled Versus Public Schooled Children. Pediatric Exercise Science, 22(1), 44-69. https://doi.org/10.1123/pes.22.1.44

Lubans, D. R., Morgan, P. J., Cliff, D. P., Barnett, L. M., \& Okely, A. D. (2010). Fundamental movement skills in children and adolescents: Review of associated health benefits. Sports Medicine, 40, 1019-1035. https://doi.org/10.2165/11536850-000000000-00000

McKenzie, T. L., Alcaraz, J. E., \& Sallis, J. F. (1998). Effects of a physical education program on children's manipulative skills. Journal of Teaching in Physical Education, 17(3), 327-341. https://doi.org/10.1123/jtpe.17.3.327

Portman, P. A. (1995). Coping behaviors of low-skilled students in physical education: avoid, announce, act out, and accept. Physical Educator, 52, 29-39.

Rink, J. E. (1993). Teaching physical education for learning. St. Louis, MO: Mosby.

Siedentop, D. (2002). Sport education: a retrospective. Journal of Teaching in Physical Education, 21, 409-418. https://doi.org/10.1123/jtpe.21.4.409

Stodden, D. F., Goodway, J. D., \& Langendorfer, S. J. (2008). A developmental perspective on the role of motor skill competence in physical activity: an emergent relationship. Quest, 60, 290-306. https://doi.org/10.1080/00336297.2008.10483582 
Swenson, S., Pope, Z., \& Zeng, N. (2016). Objectively-measured physical activity levels in physical education among homeschool children. Journal of Teaching, Research, and Media in Kinesiology, 2, 1-9.

Thomas, J. R., Thomas, K. T., \& Gallagher, J. D. (1993). Developmental considerations in skill acquisition. In R. N. Singer, M. Murphery, \& L. K. Tennant (Eds.), Handbook of Research on Sport Psychology (pp. 73-105). New York: MacMillan.

Welk, G., Schaeben, J., \& Shelley, M. (2004). Physical activity and physical fitness in school children at home and children attending public schools. Pediatric Exercise Science, 16, 310-223. https://doi.org/10.1123/pes.16.4.310

\section{Copyrights}

Copyright for this article is retained by the author(s), with first publication rights granted to the journal.

This is an open-access article distributed under the terms and conditions of the Creative Commons Attribution license (http://creativecommons.org/licenses/by/4.0/). 